\title{
Deoxystreptamine Dimers Bind to RNA Hairpin Loops
}

\author{
Xianjun Liu, Jason R. Thomas, and Paul J. Hergenrother*
}

Department of Chemistry, Roger Adams Laboratory

Urbana, IL 61801

Supporting Information 
${ }^{1} \mathrm{H}$ NMR and ${ }^{13} \mathrm{C}$ NMR spectra were recorded on Varian unity 400 and on Varian unity 500 spectrometers in $\mathrm{CDCl}_{3}, \mathrm{CD}_{3} \mathrm{OD}$, DMSO- $\mathrm{d}_{6}$ or THF- $\mathrm{d}_{8}$. The data is reported as follows : chemical shifts in ppm $(\delta)$, multiplicities are indicated as s-singlet; d-doublet; $\mathrm{t}$ triplet; q-quarted; m-multiplet; br-broad. Coupling constants $J$ are reported in $\mathrm{Hz}$. Infrared spectra were recorded on Perkin Elmer spectrum BX spectrophotometer, and the peaks reported in $\mathrm{cm}^{-1}$. Mass spectra data reported in $\mathrm{m} / \mathrm{e}$ (intensity to $100 \%$ ). Analytical thin-layer chromatography was performed on Merck silica gel plated with F254 indicator. The plates were visualized by CAM stain. Melting points were determined on a ThomasHoover capillary melting point apparatus and are uncorrected. Bis(4bromomethylphenyl)methane ${ }^{1}, \quad 4,4^{\prime}$-bis(bromomethyl)dibenzyl ${ }^{1}, \quad$ and di-p(bromomethyl)phenyl ether ${ }^{2}$ were obtained following the procedures described in literature. All other reagents were purchased from Aldrich. Starting material 2-Deoxy1,3-diazideo-5,6-di-O-acetylstreptamine (2) was made following the literature protocol. ${ }^{3}$

\section{General scheme for the synthesis of the deoxystreptamine dimers}
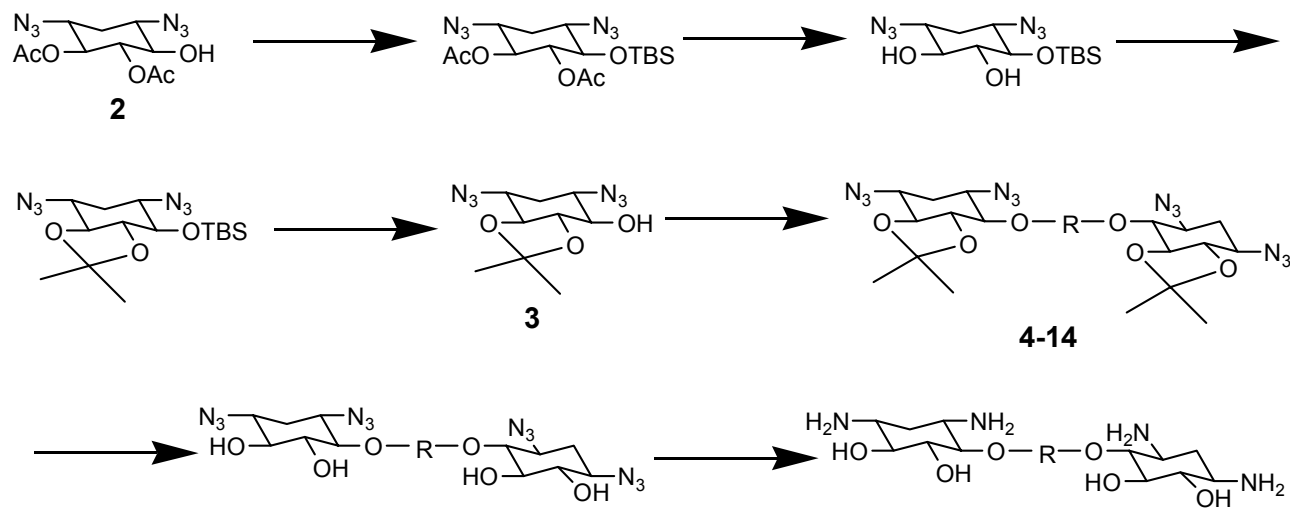

$4 a-14 a$

4b-14b

\section{Synthetic procedures and compound characterization}

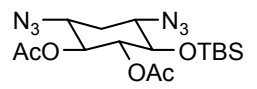

2-Deoxy-1,3-diazido-4-O-t-butyldimethylsilyl-5,6-di-O-acetylstreptamine.

Butyldimethylsilyl chloride $(5.86 \mathrm{~g}, 37.75 \mathrm{mmol})$ was added to a mixture of 2 ( $7.50 \mathrm{~g}$, $25.17 \mathrm{mmol})$ and imidazole $(6.85 \mathrm{~g}, 100.67 \mathrm{mmol})$ in DMF $(10 \mathrm{~mL})$. The reaction was stirred for $24 \mathrm{~h}$ at room temperature, diluted with water $(30 \mathrm{~mL})$, and then extracted three times with ether $(3 \times 20 \mathrm{~mL})$, and dried $\left(\mathrm{Na}_{2} \mathrm{SO}_{4}\right)$, filtered, and concentrated. The residue was chromatographed on silica gel with $10 \%$ hexanes in ethyl acetate to give the product $(9.60 \mathrm{~g}, 92 \%)$ as a white solid.

${ }^{1} \mathbf{H}$ NMR ( $\left.500 \mathrm{MHz}, \mathrm{CDCl}_{3}\right)$ : 
$\delta 4.98(\mathrm{t}, J=10.0,1 \mathrm{H}), 4.89(\mathrm{t}, J=10.0,1 \mathrm{H}), 3.59(\mathrm{~m}, 1 \mathrm{H}), 3.50(\mathrm{t}, J=10.0$, $1 \mathrm{H}), 3.38(\mathrm{~m}, 1 \mathrm{H}), 2.26(\mathrm{ddd}, J=4.5,4.5,13.0,1 \mathrm{H}), 2.16(\mathrm{~s}, 3 \mathrm{H}), 2.12(\mathrm{~s}, 3 \mathrm{H})$, $1.51(\mathrm{q}, J=12.4,1 \mathrm{H}), 0.88(\mathrm{~s}, 9 \mathrm{H}), 0.18(\mathrm{~s}, 3 \mathrm{H}), 0.06(\mathrm{~s}, 3 \mathrm{H})$.

${ }^{13} \mathbf{C}$ NMR (125 MHz, $\left.\mathrm{CDCl}_{3}\right)$ :

$\delta 170.2,170.0,77.5,77.4,77.2,77.0,74.6,74.4,74.0,62.3,58.3,32.4,25.8,21.2$, $20.8,18.1,-4.3,-4.5$.

HRMS (FAB): $\mathrm{m} / \mathrm{e}$ calcd for $\mathrm{C}_{16} \mathrm{H}_{28} \mathrm{~N}_{6} \mathrm{O}_{5} \mathrm{Si}\left(\mathrm{M}+\mathrm{H}^{+}\right)$413.1969, found 413.1979.

IR $\left(\mathrm{CH}_{2} \mathrm{Cl}_{2}\right)=2102,1742 \mathrm{~cm}^{-1}$.

$\mathbf{R}_{\boldsymbol{f}}=0.22(15 \%$ hexane in ethyl acetate $)$.

m.p. $=136-138^{\circ} \mathrm{C}$.

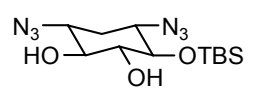

2-Deoxy-1,3-diazido-4-t-butyldimethylsilyl-streptamine. To a solution of 2-Deoxy1,3-diazido-4-O- $t$-butyldimethylsilyl-5,6-di-O-acetylstreptamine $(7.0 \mathrm{~g}, 16.97 \mathrm{mmol})$ in methanol $(15 \mathrm{~mL})$ was added a dropwise solution of sodium methoxide (approximately 1 $\mathrm{M}$ solution in methanol). After stirring for $5 \mathrm{~h}$ at $\mathrm{rt}$, the reaction was neutralized with Amberlite IR-120 $\left(\mathrm{H}^{+}\right)(2.0 \mathrm{~g})$. The solution was concentrated under reduced pressure, and the product was chromatographed on silica gel with $15 \%$ hexane in ethyl acetate to give a white solid $5.20 \mathrm{~g}(93 \%)$.

${ }^{1}$ H NMR ( $\left.400 \mathrm{MHz}, \mathrm{CD}_{3} \mathrm{OD}\right) \delta \mathrm{ppm}$ :

$3.30-3.42(\mathrm{~m}, 2 \mathrm{H}), 3.18-3.25(\mathrm{~m}, 3 \mathrm{H}), 2.18(\mathrm{ddd}, J=4.5,4.5,13.0,1 \mathrm{H}), 1.30(\mathrm{q}, J$ $=12.5,1 \mathrm{H}), 0.98(\mathrm{~s}, 9 \mathrm{H}), 0.18(\mathrm{~s}, 6 \mathrm{H})$.

${ }^{13}$ C NMR (100 MHz, $\left.\mathrm{CD}_{3} \mathrm{OD}\right) \delta \mathrm{ppm}$ :

77.1, 76.7, 76.1, 62.8, 60.9, 32.2, 25.3, 18.0, -4.8, -5.8.

HRMS (FAB): m/e calcd. for $\mathrm{C}_{12} \mathrm{H}_{24} \mathrm{~N}_{6} \mathrm{O}_{3} \mathrm{Si}\left(\mathrm{M}+\mathrm{H}^{+}\right)$329.1757, found 329.1755.

IR $\left(\mathrm{CH}_{2} \mathrm{Cl}_{2}\right)=3400,2103 \mathrm{~cm}^{-1}$.

$\mathbf{R}_{\boldsymbol{f}}=0.20$ (10\% hexane in ethyl acetate).

m. p. $=120-122^{\circ} \mathrm{C}$.

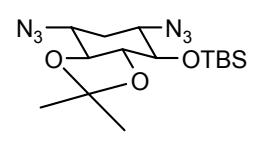

2-Deoxy-1,3-diazido-4-t-butyldimethylsilyl-5,6-O-isopropylidene-streptamine. To a solution of 2-Deoxy-1,3-diazido-4-t-butyldimethylsilyl-streptamine (5.0 g, $15.22 \mathrm{mmol})$, $p$-toluenesulfonic acid $(0.5 \mathrm{~g})$ and 2,2-dimethoxypropane $(8.0 \mathrm{~g}, 76.20 \mathrm{mmol})$ were added. The mixture was stirred at room temperature for $10 \mathrm{~h}$, at which point $\mathrm{Et}_{3} \mathrm{~N}(1.0$ $\mathrm{mL}$ ) was added to neutralize the mixture. The solution was concentrated under reduced pressure to a small amount, water was added, and the solution was extracted three times with ether $(3 \times 20 \mathrm{~mL})$, dried $\left(\mathrm{Na}_{2} \mathrm{SO}_{4}\right)$ and concentrated. Purification by silica gel column chromatography ( $1 \%$ ethyl acetate in hexanes) gave a colorless oil $5.33 \mathrm{~g}(95 \%)$.

${ }^{1}$ H NMR (500 MHz, CD $\left.{ }_{3} \mathrm{OD}\right) \delta$ ppm:

3.68-3.80 (m, 2H), 3.41-3.46 (m, 3H), $2.21(\mathrm{ddd}, \mathrm{J}=4.5,4.5,13.0,1 \mathrm{H}), 1.42(\mathrm{~s}$, $3 \mathrm{H}), 1.41(\mathrm{~s}, 3 \mathrm{H}), 1.38(\mathrm{q}, \mathrm{J}=12.4,1 \mathrm{H}), 0.93(\mathrm{~s}, 9 \mathrm{H}), 0.07(\mathrm{~s}, 3 \mathrm{H}), 0.06(\mathrm{~s}, 3 \mathrm{H})$. 
${ }^{13}$ C NMR (125 MHz, $\left.\mathrm{CD}_{3} \mathrm{OD}\right) \delta$ ppm:

111.6, 79.9, 79.6, 75.2, 64.3, 57.7, 33.6, 29.7, 25.9, 25.7, 25.0, 17.8, -5.3, -5.9.

HRMS (FAB): $\mathrm{m} / \mathrm{e}$ calcd for $\mathrm{C}_{15} \mathrm{H}_{28} \mathrm{~N}_{6} \mathrm{O}_{3} \mathrm{Si}\left(\mathrm{M}+\mathrm{H}^{+}\right)$369.2070, found 369.2074.

IR $\left(\mathrm{CH}_{2} \mathrm{Cl}_{2}\right)=2103,1251 \mathrm{~cm}^{-1}$.

$\mathbf{R}_{\boldsymbol{f}}=0.5$ (2\% ethyl acetate in hexanes).

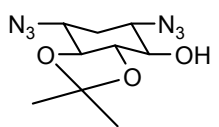

2-Deoxy-1,3-diazido-5,6-O-isopropylidene-streptamine (3). To a solution of 2-Deoxy1,3-diazido-4-t-butyldimethylsilyl-5,6-O-isopropylidene-streptamine (5.0 g, $13.57 \mathrm{mmol})$ in THF $(10 \mathrm{~mL})$ was added tetrabutylammonium fluoride $(5 \mathrm{~mL}, 1 \mathrm{M}$ in THF). The mixture was stirred at $\mathrm{rt}$ for $1 \mathrm{~h}$, after which time the solution was evaporated. The residue was dissolved in ether $(30 \mathrm{~mL})$, washed three times with water $(3 \times 5 \mathrm{~mL})$, dried over $\mathrm{Na}_{2} \mathrm{SO}_{4}$, and concentrated. Purification by silica gel column chromatography $(20 \%$ ethyl acetate in hexanes) gave white solid $3.40 \mathrm{~g}(100 \%)$.

${ }^{1}$ H NMR $\left(400 \mathrm{MHz}, \mathrm{CD}_{3} \mathrm{OD}\right) \delta \mathrm{ppm}$ :

3.75-3.80 (m, 1H), 3.61-3.63 (m, 1H), 3.42-3.44 (m, 3H), $2.22(\mathrm{ddd}, \mathrm{J}=4.5,4.5$, $13.0,1 \mathrm{H}), 1.44(\mathrm{~s}, 9 \mathrm{H}), 1.38(\mathrm{q}, \mathrm{J}=13.0,1 \mathrm{H})$.

${ }^{13}$ C NMR (100 MHz, $\left.\mathrm{CD}_{3} \mathrm{OD}\right) \delta \mathrm{ppm}$ :

$111.8,79.9,79.7,74.0,63.1,57.7,33.6,25.9,25.7$.

HRMS (FAB): $\mathrm{m} / \mathrm{e}$ calcd for $\mathrm{C}_{9} \mathrm{H}_{14} \mathrm{~N}_{6} \mathrm{O}_{3}\left(\mathrm{M}+\mathrm{H}^{+}\right)$255.1205, found 255.1205.

IR $\left(\mathrm{CH}_{2} \mathrm{Cl}_{2}\right): 3436,2102 \mathrm{~cm}^{-1}$.

$\mathbf{R}_{\boldsymbol{f}}=0.2$ (25\% ethyl acetate in hexanes).

m. p. $=108-110^{\circ} \mathrm{C}$.

\section{General procedure for the preparation of dimers:}

To a solution of starting material $3(0.50 \mathrm{~g}, 1.97 \mathrm{mmol}), \mathrm{NaH}(0.40 \mathrm{~g}, 9.85 \mathrm{mmol}$, $60 \%$ dispersion in mineral oil), catalytic amount of TBAI in anhydrous DMF, was added dropwise to the dibromo reagents $(0.98 \mathrm{mmol})$. The mixture was stirred at room temperature for $2 \mathrm{~h}$, then methanol $(1 \mathrm{~mL})$ was added to stop the reaction. The reaction mixture was poured into a solution of ice water and ether. The organic layer was washed with brine, and dried over $\mathrm{Na}_{2} \mathrm{SO}_{4}$. After removal of the solvent, purification with silica gel column chromatography (ethyl acetate in hexanes, $5-10 \%$ gradient) gave the pure products, $\mathrm{R}_{\mathrm{f}} 0.30$ ( $25 \%$ ethyl acetate in hexanes).

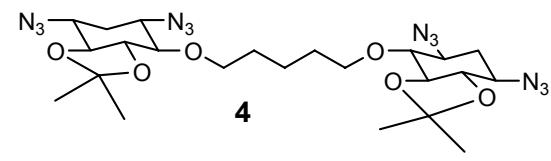

Yield $=64 \%$ (based on the recovered starting material), white solid.

${ }^{1} \mathbf{H}$ NMR ( $\left.400 \mathrm{MHz}, \mathrm{CD}_{3} \mathrm{OD}\right) \delta \mathrm{ppm}$ : 
3.82-3.86 (m, 2H), 3.68-3.74 (m, 2H), 3.58-3.62 (m, 2H), 3.42-3.58 (m, 8H), 2.08 (ddd, J = 4.4, 4.4, 13.0, 2H), 1.58-1.64 (m, 4H), 1.49-1.52 (m, 2H), $1.42(\mathrm{~m}$, $12 \mathrm{H}), 1.25(\mathrm{q}, \mathrm{J}=13.2,2 \mathrm{H})$.

${ }^{13}$ C NMR (125 MHz, $\left.\mathrm{CD}_{3} \mathrm{OD}\right) \delta \mathrm{ppm}:$

111.8 (x2), 81.8 (x2), 80.1 (x2), 79.8 (x2), 71.0 (x2), 61.4 (x2), 57.6 (x2), 33.7 (x2), $29.6(\mathrm{x} 2), 25.9(\mathrm{x} 2), 25.8(\mathrm{x} 2), 22.2$.

HRMS (FAB): $\mathrm{m} / \mathrm{e}$ calcd for $\mathrm{C}_{23} \mathrm{H}_{36} \mathrm{~N}_{12} \mathrm{O}_{6}\left(\mathrm{M}+\mathrm{H}^{+}\right)$577.2959, found 577.2957.

IR $\left(\mathrm{CH}_{2} \mathrm{Cl}_{2}\right): 2102,1099 \mathrm{~cm}^{-1}$.

m. p. $=180-182^{\circ} \mathrm{C}$.

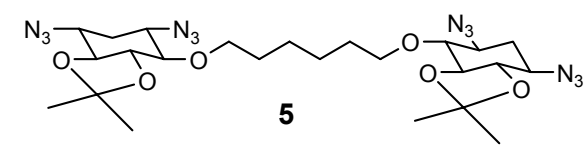

Yield $=70 \%$ (based on the recovered starting material), white solid.

${ }^{1} \mathbf{H}$ NMR $(500 \mathrm{MHz}$, DMSO-d 6 ) $\delta$ ppm:

3.78-3.83 (m, 2H), 3.70-3.76 (m, 2H), 3.58-3.62 (m, 2H), 3.43-3.58 (m, 8H), 2.10 (ddd, $\mathrm{J}=4.4,4.4,12.4,2 \mathrm{H}), 1.48-1.54(\mathrm{br}, 4 \mathrm{H}), 1.38(\mathrm{~m}, 12 \mathrm{H}), 1.25-1.34(\mathrm{~m}$, $6 \mathrm{H})$.

${ }^{13}$ C NMR $(125 \mathrm{MHz}$, DMSO-d 6 ) $\delta \mathrm{ppm:}$

111.8 (x2), 81.3 (x2), 79.8 (x2), 79.3 (x2), 71.0 (x2), 61.2 (x2), 57.4 (x2), 33.7 (x2), $30.0(\mathrm{x} 2), 27.4(\mathrm{x} 2), 27.3(\mathrm{x} 2), 25.7(\mathrm{x} 2)$.

HRMS (FAB): $\mathrm{m} / \mathrm{e}$ calcd for $\mathrm{C}_{24} \mathrm{H}_{38} \mathrm{~N}_{12} \mathrm{O}_{6}\left(\mathrm{M}+\mathrm{H}^{+}\right)$591.3115, found 591.3116.

IR $\left(\mathrm{CH}_{2} \mathrm{Cl}_{2}\right): 2092,1096 \mathrm{~cm}^{-1}$.

m. p. $=198-200^{\circ} \mathrm{C}$.

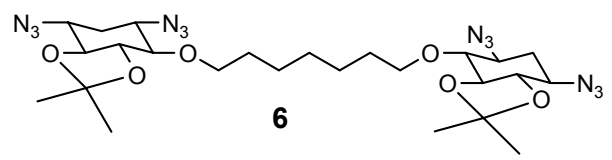

Yield $71 \%$ (based on the recovered starting material), white solid.

${ }^{1} \mathbf{H}$ NMR $\left(500 \mathrm{MHz}, \mathrm{CD}_{3} \mathrm{OD}\right) \delta \mathrm{ppm}:$

3.82-3.88 (m, 2H), 3.68-3.72 (m, $2 \mathrm{H}), 3.58-3.61(\mathrm{~m}, 2 \mathrm{H}), 3.49-3.52(\mathrm{~m}, 2 \mathrm{H})$, 3.41-3.47 (m, 6H), 2.15 (ddd, J = 4.4, 4.4, 13.0, 2H), 1.58-1.62 (m, 4H), $1.45(\mathrm{~m}$, $12 \mathrm{H}), 1.37-1.44(\mathrm{~m}, 6 \mathrm{H}), 1.31(\mathrm{q}, \mathrm{J}=13.2,2 \mathrm{H})$.

${ }^{13}$ C NMR $\left(125 \mathrm{MHz}, \mathrm{CD}_{3} \mathrm{OD}\right) \delta \mathrm{ppm}:$

111.9 (x2), 81.7 (x2), 80.1 (x2), 79.8 (x2), 71.1 (x2), $61.4(\mathrm{x} 2), 57.6$ (x2), 33.7 (x2), 29.7 (x2), 28.9, 25.9(x2), 25.8 (x2), 25.7 (x2).

HRMS (FAB): $\mathrm{m} / \mathrm{e}$ calcd for $\mathrm{C}_{25} \mathrm{H}_{40} \mathrm{~N}_{12} \mathrm{O}_{6}\left(\mathrm{M}+\mathrm{H}^{+}\right)$605.3272, found 605.3270 .

IR $\left(\mathrm{CH}_{2} \mathrm{Cl}_{2}\right): 2102,1100 \mathrm{~cm}^{-1}$.

m. p. $=187-189^{\circ} \mathrm{C}$. 


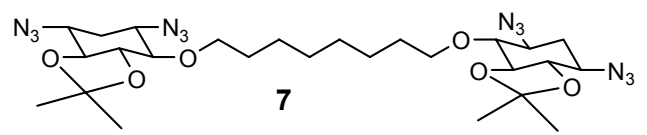

Yield $70 \%$ (based on the recovered starting material), white solid.

${ }^{1}$ H NMR $\left(400 \mathrm{MHz}, \mathrm{DMSO}-\mathrm{d}_{6}\right) \delta \mathrm{ppm}$ :

3.78-3.81 (m, 2H), 3.71-3.75 (m, 2H), 3.58-3.62 (m, 2H), 3.43-3.52 (m, 8H), 2.10 (ddd, $\mathrm{J}=4.4,4.4,12.5,2 \mathrm{H}), 1.48-1.52(\mathrm{~m}, 4 \mathrm{H}), 1.38(\mathrm{~m}, 12 \mathrm{H}), 1.21-1.37$ (br, $10 \mathrm{H})$.

${ }^{13}$ C NMR (100 MHz, DMSO-d 6 ) $\delta$ ppm:

$111.8(\mathrm{x} 2), 81.3(\mathrm{x} 2), 79.8$ (x2), 79.3 (x2), $71.0(\mathrm{x} 2), 61.2(\mathrm{x} 2), 57.4(\mathrm{x} 2), 33.7$ (x2), $30.1(\mathrm{x} 2), 29.4(\mathrm{x} 2), 27.4(\mathrm{x} 2), 27.3(\mathrm{x} 2), 25.9(\mathrm{x} 2)$.

HRMS (FAB): $\mathrm{m} / \mathrm{e}$ calcd for $\mathrm{C}_{26} \mathrm{H}_{42} \mathrm{~N}_{12} \mathrm{O}_{6}\left(\mathrm{M}+\mathrm{H}^{+}\right)$619.3428, found 619.3429.

IR $\left(\mathrm{CH}_{2} \mathrm{Cl}_{2}\right): 2101,1090 \mathrm{~cm}^{-1}$.

m. p. $=110-112^{\circ} \mathrm{C}$.

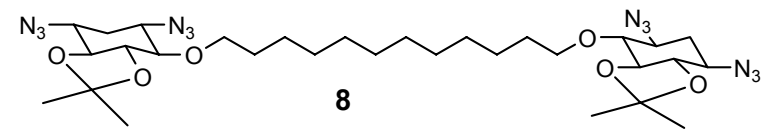

Yield $70 \%$ (based on the recovered starting material), white solid.

${ }^{1}$ H NMR (500 MHz, DMSO-d 6 ) $\delta$ ppm:

3.76-3.82 (m, 2H), 3.68-3.73 (m, 2H), 3.58-3.61 (m, 2H), 3.45-3.51 (m, 8H), $2.10(\mathrm{ddd}, \mathrm{J}=4.4,4.4,12.8,2 \mathrm{H}), 1.46-1.51(\mathrm{~m}, 4 \mathrm{H}), 1.36(\mathrm{~m}, 12 \mathrm{H}), 1.28-1.32(\mathrm{~m}$, $6 \mathrm{H}), 1.20-1.24$ (br, 12H).

${ }^{13}$ C NMR (125 MHz, DMSO-d 6 ) $\delta$ ppm:

111.8 (x2), 81.3 (x2), 79.8 (x2), 79.3 (x2), 71.0 (x2), 61.2 (x2), 57.4 (x2), 33.7 (x2), 30.0 (x2), 29.6 (x2), 29.5 (x2), 29.3 (x2), 27.4 (x2), 27.3 (x2), 25.9 (x2).

HRMS (ESI): $\mathrm{m} / \mathrm{e}$ calcd for $\mathrm{C}_{30} \mathrm{H}_{50} \mathrm{~N}_{12} \mathrm{O}_{6}\left(\mathrm{M}+\mathrm{H}^{+}\right)$675.4055, found 675.4068.

IR $\left(\mathrm{CH}_{2} \mathrm{Cl}_{2}\right): 2099,1100 \mathrm{~cm}^{-1}$.

m. p. $=101-103^{\circ} \mathrm{C}$.

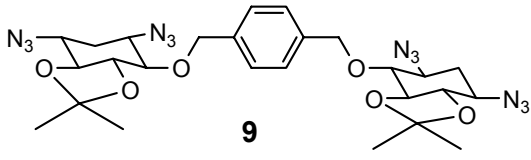

Yield $95 \%$, white solid.

${ }^{1}$ H NMR ( $400 \mathrm{MHz}$, DMSO-d $\left.\mathrm{d}_{6}\right) \delta$ ppm:

$7.35(\mathrm{~s}, 4 \mathrm{H}), 4.80(\mathrm{~d}, \mathrm{~J}=10.5,2 \mathrm{H}), 4.65(\mathrm{~d}, \mathrm{~J}=10.5,2 \mathrm{H}), 3.79-3.83(\mathrm{~m}, 2 \mathrm{H})$, 3.62-3.73 (m, 2H), 3.58-3.65 (m, 4H), 3.55-3.59 (m, 4H), $2.16(\mathrm{ddd}, \mathrm{J}=4.4,4.4$, $13.0,2 \mathrm{H}), 1.37-1.41(\mathrm{~m}, 14 \mathrm{H})$.

${ }^{13}$ C NMR (100 MHz, DMSO-d $\left.{ }_{6}\right) \delta$ ppm:

$137.9(\mathrm{x} 2), 128.0(\mathrm{x} 2), 112.0(\mathrm{x} 2), 80.6(\mathrm{x} 2), 80.0(\mathrm{x} 2), 79.3(\mathrm{x} 2), 72.2(\mathrm{x} 2), 61.2$ (x2), $57.3(\mathrm{x} 2), 33.7(\mathrm{x} 2), 27.5(\mathrm{x} 2), 27.4(\mathrm{x} 2)$.

HRMS (FAB): $\mathrm{m} / \mathrm{e}$ calcd for $\mathrm{C}_{26} \mathrm{H}_{34} \mathrm{~N}_{12} \mathrm{O}_{6}\left(\mathrm{M}+\mathrm{H}^{+}\right)$611.2803, found 611.2802. 
IR $\left(\mathrm{CH}_{2} \mathrm{Cl}_{2}\right): 2102,1088 \mathrm{~cm}^{-1}$.

m. p. $=158-160^{\circ} \mathrm{C}$.

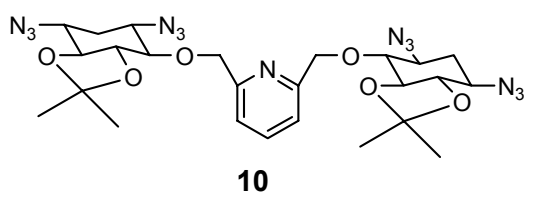

Yield $94 \%$, white solid.

${ }^{1}$ H NMR (500 MHz, DMSO-d 6 ) $\delta$ ppm:

$7.84(\mathrm{t}, \mathrm{J}=10.0,1 \mathrm{H}), 7.39(\mathrm{~d}, \mathrm{~J}=10.5,2 \mathrm{H}), 4.85(\mathrm{~d}, \mathrm{~J}=10.5,2 \mathrm{H}), 4.71(\mathrm{~d}, \mathrm{~J}=$ $10.5,2 \mathrm{H}), 3.81-3.84(\mathrm{~m}, 2 \mathrm{H}), 3.75-3.79(\mathrm{~m}, 4 \mathrm{H}), 3.58-3.61(\mathrm{~m}, 4 \mathrm{H}), 2.18$ (ddd, J $=4.4,4.4,13.0,2 \mathrm{H}), 1.38-1.42(\mathrm{~m}, 14 \mathrm{H})$.

${ }^{13}$ C NMR (100 MHz, DMSO-d 6 ) $\delta$ ppm:

157.9, $120.2(\mathrm{x} 4), 112.1(\mathrm{x} 2), \quad 81.2(\mathrm{x} 2), 79.8(\mathrm{x} 2), 79.3(\mathrm{x} 2), 73.4(\mathrm{x} 2), 61.2$ (x2), $57.3(\mathrm{x} 2), 33.7$ (x2), $27.4(\mathrm{x} 2), 27.3(\mathrm{x} 2)$.

HRMS (ESI): $\mathrm{m} / \mathrm{e}$ calcd for $\mathrm{C}_{25} \mathrm{H}_{33} \mathrm{~N}_{13} \mathrm{O}_{6}\left(\mathrm{M}+\mathrm{H}^{+}\right)$612.2755, found 612.2772 .

IR $\left(\mathrm{CH}_{2} \mathrm{Cl}_{2}\right): 2102,1089 \mathrm{~cm}^{-1}$.

m. p. $=124-126^{\circ} \mathrm{C}$.

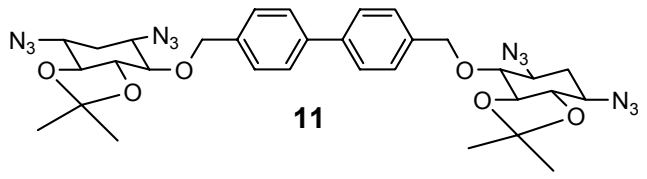

Yield $97 \%$, white solid.

${ }^{1} \mathbf{H}$ NMR $\left(500 \mathrm{MHz}, \mathrm{CD}_{3} \mathrm{OD}\right) \delta \mathrm{ppm}$ :

7.59-7.62 (m, 2H), 7.37-7.40 (m, 2H), 7.32-7.35 (m, 2H), 7.15-7.18 (m,2H), 4.62$4.68(\mathrm{~m}, 2 \mathrm{H}), 4.38-4.42(\mathrm{~m}, 2 \mathrm{H}), 3.61-3.66(\mathrm{~m}, 2 \mathrm{H}), 3.49-3.54(\mathrm{~m}, 2 \mathrm{H}), 3.34-3.42$ $(\mathrm{m}, 6 \mathrm{H}), 2.15-2.20(\mathrm{~m}, 2 \mathrm{H}), 1.22-1.38(\mathrm{~m}, 14 \mathrm{H})$.

${ }^{13} \mathbf{C}$ NMR $\left(125 \mathrm{MHz}, \mathrm{CD}_{3} \mathrm{OD}\right) \delta \mathrm{ppm}:$

$140.9,140.7,136.9,136.6,129.7,129.4,128.7,128.5,128.3,127.4,127.1,127.0$, 111.9 (x2), 81.0, 80.9, 80.7, 80.1, 80.0, 79.8, 70.5, 70.4, 70.2, 61.4, 61.3, 57.5, $33.7(\mathrm{x} 2), 26.0(\mathrm{x} 2), 25.9(\mathrm{x} 2)$.

HRMS (FAB) $\mathrm{m} / \mathrm{e}$ calcd for $\mathrm{C}_{32} \mathrm{H}_{38} \mathrm{~N}_{12} \mathrm{O}_{6}\left(\mathrm{M}+\mathrm{H}^{+}\right)$687.3116, found 687.3119 .

IR $\left(\mathrm{CH}_{2} \mathrm{Cl}_{2}\right): 2101,1085 \mathrm{~cm}^{-1}$.

m. p. $=180-182{ }^{\circ} \mathrm{C}$.

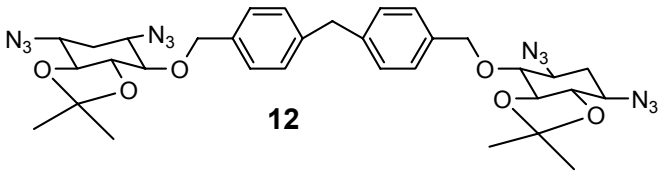

Yield $96 \%$, white solid. 
${ }^{1}$ H NMR $(500 \mathrm{MHz}$, DMSO-d 6 ) $\delta$ ppm:

$7.23(\mathrm{~d}, \mathrm{~J}=10.5,4 \mathrm{H}), 7.18(\mathrm{~d}, \mathrm{~J}=10.5,4 \mathrm{H}), 4.78(\mathrm{~d}, \mathrm{~J}=12.0,2 \mathrm{H}), 4.59(\mathrm{~d}, \mathrm{~J}=$ $12.0,2 \mathrm{H}), 3.90(\mathrm{~s}, 2 \mathrm{H}), 3.79-3.82(\mathrm{~m}, 2 \mathrm{H}), 3.63-3.68(\mathrm{~m}, 4 \mathrm{H}), 3.53-3.58(\mathrm{~m}, 4 \mathrm{H})$, 2.15 (ddd, $\mathrm{J}=4.4,4.4,13.0,2 \mathrm{H}), 1.38-1.42(\mathrm{~m}, 14 \mathrm{H})$.

${ }^{13}$ C NMR (125 MHz, DMSO-d 6 ) $\delta$ ppm:

141.3 (x2), 136.3 (x2), 129.2 (x2), 128.3 (x2), 112.0 (x2), 80.5 (x2), 80.0 (x2), 79.3 (x2), 72.3 (x2), 61.2 (x2), 57.3 (x2), 33.7 (x2), 27.4, 27.3 (x2).

HRMS (ESI): $\mathrm{m} / \mathrm{e}$ calcd for $\mathrm{C}_{33} \mathrm{H}_{40} \mathrm{~N}_{12} \mathrm{O}_{6}(\mathrm{M}+\mathrm{Na})$ 723.3091, found 723.3088 .

IR $\left(\mathrm{CH}_{2} \mathrm{Cl}_{2}\right): 2101,1089 \mathrm{~cm}^{-1}$.

m. p. $=138-140{ }^{\circ} \mathrm{C}$.

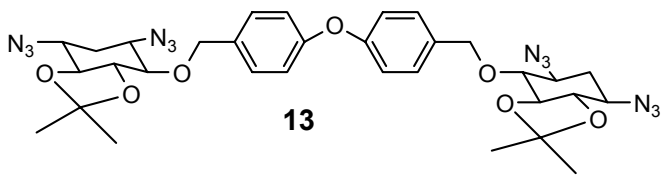

Yield $95 \%$, white solid.

${ }^{1}$ H NMR $(500 \mathrm{MHz}$, DMSO-d 6 ) $\delta$ ppm:

$7.38(\mathrm{~d}, \mathrm{~J}=10.5,4 \mathrm{H}), 6.98(\mathrm{~d}, \mathrm{~J}=10.5,4 \mathrm{H}), 4.78(\mathrm{~d}, \mathrm{~J}=12.0,2 \mathrm{H}), 4.60(\mathrm{~d}, \mathrm{~J}=$ 12.0, 2H), 3.80-3.82 (m, 2H), 3.63-3.68 (m, 4H), 3.53-3.58 (m, 4H), 2.18 (ddd, J $=4.4,4.4,13.0,2 \mathrm{H}), 1.38-1.42(\mathrm{~m}, 14 \mathrm{H})$.

${ }^{13}$ C NMR (125 MHz, DMSO-d 6 ) $\delta$ ppm:

156.8 (x2), 133.8 (x2), 130.1 (x2), 119.0 (x2), 112.0 (x2), 80.5 (x2), 80.0 (x2), 79.3 (x2), 72.1 (x2), 61.2 (x2), 57.3 (x2), 33.7 (x2), 27.5 (x2), 27.3 (x2).

HRMS (ESI) $\mathrm{m} / \mathrm{e}$ calcd for $\mathrm{C}_{32} \mathrm{H}_{38} \mathrm{~N}_{12} \mathrm{O}_{7}(\mathrm{M}+\mathrm{Na}$ ) 725.3374, found 725.3365 .

IR $\left(\mathrm{CH}_{2} \mathrm{Cl}_{2}\right): 2102,1098 \mathrm{~cm}^{-1}$.

m. p. $=134-136^{\circ} \mathrm{C}$.

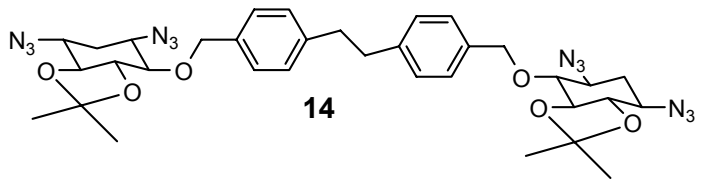

Yield $96 \%$, white solid.

${ }^{1} \mathbf{H}$ NMR $\left(500 \mathrm{MHz}, \mathrm{DMSO}-\mathrm{d}_{6}\right) \delta \mathrm{ppm}:$

$7.23(\mathrm{~d}, \mathrm{~J}=10.5,4 \mathrm{H}), 7.18(\mathrm{~d}, \mathrm{~J}=10.5,4 \mathrm{H}), 4.78(\mathrm{~d}, \mathrm{~J}=12.0,2 \mathrm{H}), 4.59(\mathrm{~d}, \mathrm{~J}=$ $12.0,2 \mathrm{H}), 3.80-3.83(\mathrm{~m}, 2 \mathrm{H}), 3.64-3.68(\mathrm{~m}, 4 \mathrm{H}), 3.55-3.58(\mathrm{~m}, 4 \mathrm{H}), 3.82(\mathrm{~s}, 4 \mathrm{H})$, 2.15 (ddd, $\mathrm{J}=4.4,4.4,13.0,2 \mathrm{H}), 1.38-1.42(\mathrm{~m}, 14 \mathrm{H})$.

${ }^{13}$ C NMR (125 MHz, DMSO-d 6 ) $\delta$ ppm:

141.5 (x2), 136.1 (x2), 128.9 (x2), 128.2 (x2), 112.0 (x2), 80.5 (x2), 80.0 (x2), 79.3 (x2), 72.3 (x2), 61.2 (x2), 57.3 (x2), 33.7 (x2), 27.4 (x2), 27.3 (x2).

HRMS (ESI) $\mathrm{m} / \mathrm{e}$ calcd for $\mathrm{C}_{34} \mathrm{H}_{42} \mathrm{~N}_{12} \mathrm{O}_{6}(\mathrm{M}+\mathrm{Na}) 737.3248$, found 737.3304.

IR $\left(\mathrm{CH}_{2} \mathrm{Cl}_{2}\right): 2102,1085 \mathrm{~cm}^{-1}$.

m. p. $=142-144{ }^{\circ} \mathrm{C}$. 


\section{General Procedure for deprotection:}

To a solution of the above dimer $(0.5 \mathrm{mmol})$ in $2: 1$ dioxane-water $(10 \mathrm{~mL})$ was added glacial acetic acid $(8 \mathrm{~mL})$ and the mixture was then stirred at $75-80^{\circ} \mathrm{C}$ for $10 \mathrm{~h}$. The reaction mixture was concentrated to dryness to provide a residue that was of sufficient purity to use directly in the next step. $\mathrm{R}_{\mathrm{f}} 0.24\left(10 \% \mathrm{MeOH}\right.$ in $\left.\mathrm{CH}_{2} \mathrm{Cl}_{2}\right)$.

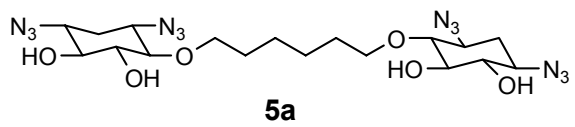

Yield $100 \%$, white solid.

${ }^{1}$ H NMR $\left(500 \mathrm{MHz}, \mathrm{THF}-\mathrm{d}_{8}\right) \delta \mathrm{ppm}$ :

$4.98(\mathrm{~m}, 2 \mathrm{H}), 4.65(\mathrm{~m}, 2 \mathrm{H}), 3.93-3.96(\mathrm{~m}, 2 \mathrm{H}), 3.64-3.68(\mathrm{~m}, 2 \mathrm{H}), 3.39-3.41(\mathrm{~m}$, $2 \mathrm{H}), 3.28-3.31(\mathrm{~m}, 2 \mathrm{H}), 3.19-3.26(\mathrm{~m}, 4 \mathrm{H}), 3.0(\mathrm{t}, \mathrm{J}=9.2,2 \mathrm{H}), 1.98(\mathrm{ddd}, \mathrm{J}=4.4$, $4.4,13.0,2 \mathrm{H}), 1.59-1.62(\mathrm{br}, 4 \mathrm{H}), 1.39-1.42(\mathrm{br}, 4 \mathrm{H}), 1.18(\mathrm{q}, \mathrm{J}=12.4,2 \mathrm{H})$.

${ }^{13}$ C NMR $\left(125 \mathrm{MHz}, \mathrm{THF}-\mathrm{d}_{8}\right) \delta \mathrm{ppm}$ :

84.7 (x2), 77.2 (x2), 76.7 (x2), $73.1(\mathrm{x} 2), 60.9$ (x2), 60.6 (x2), 32.7 (x2), 30.4 (x2), $26.1(\mathrm{x} 2)$.

HRMS (FAB): $\mathrm{m} / \mathrm{e}$ calcd for $\mathrm{C}_{18} \mathrm{H}_{30} \mathrm{~N}_{12} \mathrm{O}_{6}\left(\mathrm{M}+\mathrm{H}^{+}\right)$511.2490, found 511.2526.

IR $\left(\mathrm{CH}_{2} \mathrm{Cl}_{2}\right): 3400,2095,1090 \mathrm{~cm}^{-1}$.

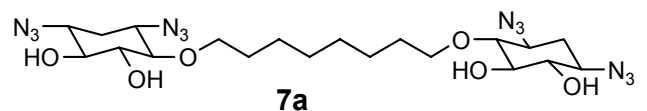

Yield $100 \%$, white solid.

${ }^{1}$ H NMR $\left(400 \mathrm{MHz}, \mathrm{THF}_{-} \mathrm{d}_{8}\right) \delta \mathrm{ppm}$ :

$4.98(\mathrm{~m}, 2 \mathrm{H}), 4.65(\mathrm{~m}, 2 \mathrm{H}), 3.94-3.96(\mathrm{~m}, 2 \mathrm{H}), 3.63-3.67(\mathrm{~m}, 2 \mathrm{H}), 3.38-3.41(\mathrm{~m}$, $2 \mathrm{H}$ ), 3.28-3.31 (m, 2H), 3.18-3.25 (m, 4H), $3.0(\mathrm{t}, \mathrm{J}=9.8,2 \mathrm{H}), 1.98$ (ddd, $\mathrm{J}=4.4$, $4.4,13.0,2 \mathrm{H}), 1.58-1.62(\mathrm{~m}, 4 \mathrm{H}), 1.32-1.40(\mathrm{br}, 8 \mathrm{H}), 1.18(\mathrm{q}, \mathrm{J}=12.4,2 \mathrm{H})$.

${ }^{13}$ C NMR $\left(100 \mathrm{MHz}, \mathrm{THF}-\mathrm{d}_{8}\right) \delta \mathrm{ppm}$ :

84.7 (x2), 77.2 (x2), 76.8 (x2), 73.1 (x2), 60.9 (x2), 60.6 (x2), 32.7 (x2), 30.4 (x2), 29.7 (x2), 26.2 (x2).

HRMS (FAB): $\mathrm{m} / \mathrm{e}$ calcd for $\mathrm{C}_{20} \mathrm{H}_{34} \mathrm{~N}_{12} \mathrm{O}_{6}\left(\mathrm{M}+\mathrm{H}^{+}\right)$539.2802, found 539.2805.

IR $\left(\mathrm{CH}_{2} \mathrm{Cl}_{2}\right): 3410,2102,1088 \mathrm{~cm}^{-1}$.

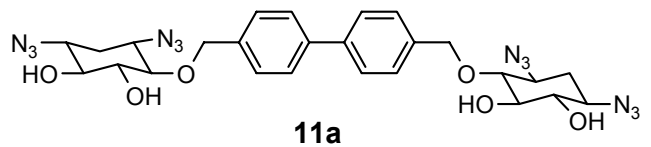

Yield $100 \%$, white solid.

${ }^{1}$ H NMR (500 MHz, THF-d 8 ) $\delta$ ppm:

$7.71(\mathrm{~m}, 2 \mathrm{H}), 7.35(\mathrm{~m}, 2 \mathrm{H}), 7.26(\mathrm{~m}, 2 \mathrm{H}), 7.16(\mathrm{~m}, 2 \mathrm{H}), 4.98(\mathrm{~m}, 2 \mathrm{H}), 4.78(\mathrm{~m}$, $2 \mathrm{H}), 4.58(\mathrm{~m}, 2 \mathrm{H}), 4.35-4.41(\mathrm{~m}, 2 \mathrm{H}), 3.42-3.47(\mathrm{~m}, 2 \mathrm{H}), 3.22-3.31(\mathrm{~m}, 4 \mathrm{H})$, 3.16-3.18 (m, 2H), 3.01-3.05 (m, 2H), $2.00(\mathrm{~m}, 2 \mathrm{H}), 1.18-1.20(\mathrm{~m}, 2 \mathrm{H})$. 
${ }^{13}$ C NMR $\left(125 \mathrm{MHz}, \mathrm{THF}-\mathrm{d}_{8}\right) \delta \mathrm{ppm}:$

139.7, 139.6, 137.3, 137.2, 129.3, 129.2, 128.0, 127.8, 127.3, 127.2, 126.7, 126.4, 84.2, 84.0, 77.0, 76.7, 76.6, 76.5, 76.4, 72.3, 72.2, 72.0, 60.8, 60.6, 32.5 (x2).

HRMS (ESI): $\mathrm{m} / \mathrm{e}$ calcd for $\mathrm{C}_{26} \mathrm{H}_{30} \mathrm{~N}_{12} \mathrm{O}_{6}(\mathrm{M}+\mathrm{Na}) 629.2309$, found 629.2299 .

IR $\left(\mathrm{CH}_{2} \mathrm{Cl}_{2}\right): 3370,2102,1090 \mathrm{~cm}^{-1}$.

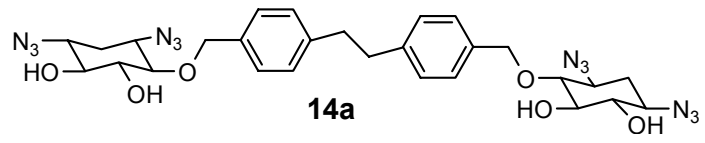

Yield $100 \%$, white solid.

${ }^{1}$ H NMR ( $\left.500 \mathrm{MHz}, \mathrm{THF}-\mathrm{d}_{8}\right) \delta$ ppm:

$7.30(\mathrm{~d}, \mathrm{~J}=10.5,4 \mathrm{H}), 7.18(\mathrm{~d}, \mathrm{~J}=10.5,4 \mathrm{H}), 5.01-5.03(\mathrm{~m}, 2 \mathrm{H}), 4.96(\mathrm{~d}, \mathrm{~J}=12.0$, $2 \mathrm{H}), 4.85-4.87(\mathrm{~m}, 2 \mathrm{H}), 4.76(\mathrm{~d}, \mathrm{~J}=12.0,2 \mathrm{H}), 3.42-3.45(\mathrm{~m}, 2 \mathrm{H}), 3.33-3.36(\mathrm{~m}$, $4 \mathrm{H}$ ), 3.18-3.23 (m, 4H), 2.88 (s, 4H), 2.01 (ddd, J = 4.4, 4.4, 13.0, 2H), 1.21 (q, J $=12.4,2 \mathrm{H})$.

${ }^{13}$ C NMR (125 MHz, THF-d 8 ) $\delta$ ppm:

141.0 (x2), 136.7 (x2), 128.0 (x4), 83.9 (x2), 77.1 (x2), 76.9 (x2), $74.6(\mathrm{x} 2), 60.9$ (x2), 60.7 (x2), 37.9 (x2), 32.7 (x2).

HRMS (ESI): $\mathrm{m} / \mathrm{e}$ calcd for $\mathrm{C}_{28} \mathrm{H}_{34} \mathrm{~N}_{12} \mathrm{O}_{6}(\mathrm{M}+\mathrm{Na})$ 657.2622, found 657.2653 .

IR $\left(\mathrm{CH}_{2} \mathrm{Cl}_{2}\right): 3300,2102,1085 \mathrm{~cm}^{-1}$.

\section{General procedure for the azide reduction:}

The deprotected dimer $(0.5 \mathrm{mmol})$ was dissolved in 4:1 THF-water $(5.0 \mathrm{~mL})$ and $0.1 \mathrm{M}$ aqueous $\mathrm{NaOH}(0.5 \mathrm{~mL})$. $\mathrm{PMe}_{3}(1 \mathrm{M}$ in THF, 5 equivalences) was then added. The reaction mixture was stirred at $45-50{ }^{\circ} \mathrm{C}$ for $5 \mathrm{hrs}$; when complete, the reaction mixture was cooled to room temperature and loaded on a short column $(5 \mathrm{~cm}$ in height) packed silica gel and Celite. The column was eluted with a series of solutions as the follows:

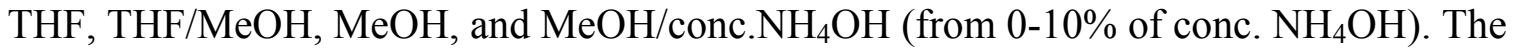
fractions containing desired product were analyzed by TLC and collected. Removal of solvents gave the final product. $\mathrm{R}_{\mathrm{f}} 0.2\left(25 \% \mathrm{NH}_{4} \mathrm{OH}\right.$ in $\left.\mathrm{MeOH}\right)$.

Yield $88 \%$, colorless foam.

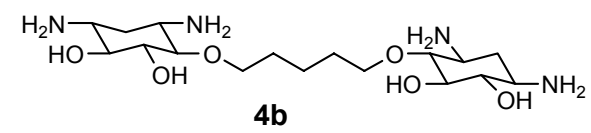

${ }^{1} \mathbf{H}$ NMR $\left(500 \mathrm{MHz}, \mathrm{CD}_{3}\right.$ OD) $\delta \mathrm{ppm}$ :

3.98-4.01 (m, 2H), 3.60-3.64 (m, 2H), $3.22(\mathrm{t}, \mathrm{J}=9.8,2 \mathrm{H}), 3.00(\mathrm{t}, \mathrm{J}=9.8,2 \mathrm{H})$,

$2.82(\mathrm{t}, \mathrm{J}=9.8,2 \mathrm{H}), 2.58-2.68(\mathrm{~m}, 4 \mathrm{H}), 1.98(\mathrm{ddd}, \mathrm{J}=4.4,4.4,13.0,2 \mathrm{H}), 1.61-$

$1.68(\mathrm{~m}, 4 \mathrm{H}), 1.46-1.50(\mathrm{~m}, 2 \mathrm{H}), 1.18(\mathrm{q}, \mathrm{J}=12.4,2 \mathrm{H})$.

${ }^{13} \mathbf{C}$ NMR (125 MHz, $\mathrm{CD}_{3}$ OD ) $\delta \mathrm{ppm:}$

86.7 (x2), 78.4 (x2), 76.9 (x2), 72.7 (x2), 51.3 (x2), 50.7 (x2), 36.1 (x2), 29.9 $(\mathrm{x} 2), 22.6$.

HRMS (FAB): $\mathrm{m} / \mathrm{e}$ calcd for $\mathrm{C}_{17} \mathrm{H}_{36} \mathrm{~N}_{4} \mathrm{O}_{6}\left(\mathrm{M}+\mathrm{H}^{+}\right)$393.2713, found 393.2713. 
IR (net): 3310 (br), $1089 \mathrm{~cm}^{-1}$.

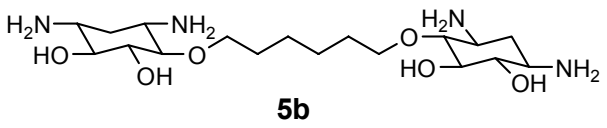

Yield $80 \%$, colorless foam.

${ }^{1}$ H NMR ( $500 \mathrm{MHz}, \mathrm{CD}_{3}$ OD) $\delta$ ppm:

3.98-4.01 (m, 2H), 3.60-3.62 (m, 2H), $3.22(\mathrm{t}, \mathrm{J}=9.8,2 \mathrm{H}), 3.02(\mathrm{t}, \mathrm{J}=9.8,2 \mathrm{H})$, $2.84(\mathrm{t}, \mathrm{J}=9.8,2 \mathrm{H}), 2.58-2.64(\mathrm{~m}, 4 \mathrm{H}), 1.98(\mathrm{ddd}, \mathrm{J}=4.4,4.4,13.0,2 \mathrm{H}), 1.61-$ 1.65 (br, 4H), 1.38-1.42 (br, 4H), 1.18 (q, J = 12.4, 2H).

${ }^{13}$ C NMR (125 MHz, CD 3 OD ) $\delta$ ppm:

$86.7(\mathrm{x} 2), 78.5(\mathrm{x} 2), 76.9(\mathrm{x} 2), 72.8$ (x2), $51.3(\mathrm{x} 2), 50.7(\mathrm{x} 2), 36.2(\mathrm{x} 2), 30.2$ (x2), $25.9(\mathrm{x} 2)$.

HRMS (FAB): $\mathrm{m} / \mathrm{e}$ calcd for $\mathrm{C}_{18} \mathrm{H}_{38} \mathrm{~N}_{4} \mathrm{O}_{6}\left(\mathrm{M}+\mathrm{H}^{+}\right)$407.2870, found 407.2871.

IR (net): 3300 (br), $1090 \mathrm{~cm}^{-1}$.

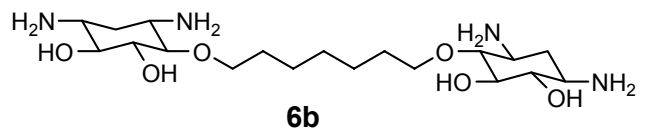

Yield $85 \%$, colorless foam.

${ }^{1}$ H NMR ( $500 \mathrm{MHz}, \mathrm{CD}_{3}$ OD) $\delta$ ppm:

3.98-4.01 (m, 2H), 3.59-3.62 (m, 2H), $3.22(\mathrm{t}, \mathrm{J}=9.8,2 \mathrm{H}), 3.02(\mathrm{t}, \mathrm{J}=9.8,2 \mathrm{H})$, $2.85(\mathrm{t}, \mathrm{J}=9.8,2 \mathrm{H}), 2.58-2.65(\mathrm{~m}, 4 \mathrm{H}), 1.98(\mathrm{ddd}, \mathrm{J}=4.4,4.4,13.0,2 \mathrm{H}), 1.60-$ 1.65 (br, 4H), 1.38-1.41 (br, 6H), 1.19 (q, J = 12.4, 2H).

${ }^{13}$ C NMR (125 MHz, CD 3 OD) $\delta$ ppm:

86.7 (x2), 78.4 (x2), 76.9 (x2), 72.9 (x2), $51.3(\mathrm{x} 2), 50.7(\mathrm{x} 2), 36.0(\mathrm{x} 2), 30.2$ (x2), 29.2, $26.0(\mathrm{x} 2)$.

HRMS (FAB): $\mathrm{m} / \mathrm{e}$ calcd for $\mathrm{C}_{19} \mathrm{H}_{40} \mathrm{~N}_{4} \mathrm{O}_{6}\left(\mathrm{M}+\mathrm{H}^{+}\right)$421.3026, found 421.3026.

IR (net): 3320 (br), $1100 \mathrm{~cm}^{-1}$.

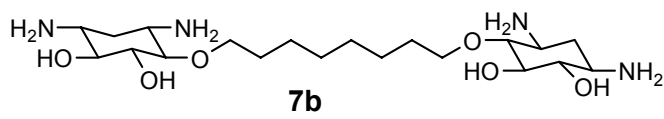

Yield $80 \%$, colorless foam.

${ }^{1} \mathbf{H}$ NMR ( $500 \mathrm{MHz}, \mathrm{CD}_{3}$ OD) $\delta$ ppm:

3.97-4.00 (m, 2H), 3.58-3.62 (m, 2H), $3.22(\mathrm{t}, \mathrm{J}=9.8,2 \mathrm{H}), 3.03(\mathrm{t}, \mathrm{J}=9.8,2 \mathrm{H})$, $2.85(\mathrm{t}, \mathrm{J}=9.8,2 \mathrm{H}), 2.58-2.65(\mathrm{~m}, 4 \mathrm{H}), 1.98(\mathrm{ddd}, \mathrm{J}=4.4,4.4,13.2,2 \mathrm{H}), 1.58-$ $1.63(\mathrm{~m}, 4 \mathrm{H}), 1.35-1.41(\mathrm{br}, 8 \mathrm{H}), 1.19(\mathrm{q}, \mathrm{J}=12.4,2 \mathrm{H})$.

${ }^{13}$ C NMR (125 MHz, CD 3 OD) $\delta$ ppm:

86.6 (x2), 78.4 (x2), 76.9 (x2), 72.9 (x2), 51.3 (x2), 50.7 (x2), $36.0(\mathrm{x} 2), 30.2$ (x2), $29.3(\mathrm{x} 2), 25.9(\mathrm{x} 2)$.

HRMS (FAB): $\mathrm{m} / \mathrm{e}$ calcd for $\mathrm{C}_{20} \mathrm{H}_{42} \mathrm{~N}_{4} \mathrm{O}_{6}\left(\mathrm{M}+\mathrm{H}^{+}\right)$435.3182, found 435.3185 . 
IR (net): 3310 (br), $1089 \mathrm{~cm}^{-1}$.

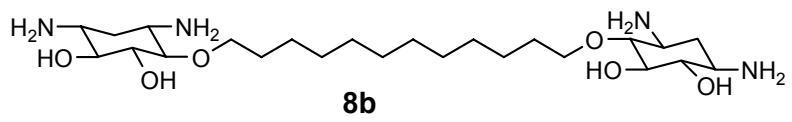

Yield $85 \%$, colorless foam.

${ }^{1} \mathbf{H}$ NMR ( $500 \mathrm{MHz}, \mathrm{CD}_{3}$ OD) $\delta \mathrm{ppm}:$

3.97-4.00 (m, 2H), 3.58-3.62 (m, 2H), $3.22(\mathrm{t}, \mathrm{J}=9.8,2 \mathrm{H}), 3.02(\mathrm{t}, \mathrm{J}=9.8,2 \mathrm{H})$,

$2.85(\mathrm{t}, \mathrm{J}=9.8,2 \mathrm{H}), 2.58-2.65(\mathrm{~m}, 4 \mathrm{H}), 1.98(\mathrm{ddd}, \mathrm{J}=4.4,4.4,13.0,2 \mathrm{H}), 1.58-$

$1.63(\mathrm{~m}, 4 \mathrm{H}), 1.25-1.40(\mathrm{br}, 16 \mathrm{H}), 1.19(\mathrm{q}, \mathrm{J}=12.4,2 \mathrm{H})$.

${ }^{13} \mathbf{C}$ NMR (125 MHz, $\mathrm{CD}_{3}$ OD ) $\delta \mathrm{ppm}:$

86.8 (x2), 78.5 (x2), 76.9 (x2), 72.9 (x2), 51.3 (x2), 50.7 (x2), 36.2 (x2), 30.2

(x2), 29.6 (x2), $25.9(\mathrm{x} 2), 29.4(\mathrm{x} 2), 26.0$ (x2).

HRMS (ESI) m/e calcd for $\mathrm{C}_{24} \mathrm{H}_{50} \mathrm{~N}_{4} \mathrm{O}_{6}\left(\mathrm{M}+\mathrm{H}^{+}\right)$491.3809, found 491.3811 .

IR (net): 3300 (br), $1110 \mathrm{~cm}^{-1}$.

Yield $85 \%$, colorless foam.

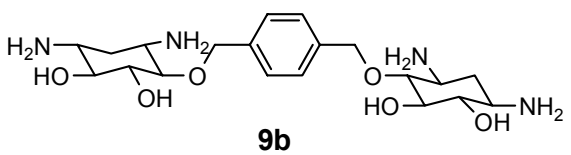

${ }^{1} \mathbf{H}$ NMR $\left(400 \mathrm{MHz}, \mathrm{CD}_{3}\right.$ OD) $\delta \mathrm{ppm}$ :

$7.40(\mathrm{~s}, 4 \mathrm{H}), 5.02(\mathrm{~d}, \mathrm{~J}=10.5,2 \mathrm{H}), 4.65(\mathrm{~d}, \mathrm{~J}=10.5,2 \mathrm{H}), 3.37-3.39(\mathrm{~m}, 2 \mathrm{H})$,

3.01-3.05 (m, 4H), 2.58-2.69 (m, 4H), 1.98 (ddd, J = 4.4, 4.4, 12.8, 2H), 1.20 (q, J

$=12.4,2 \mathrm{H})$.

${ }^{13}$ C NMR (100 MHz, $\left.\mathrm{CD}_{3} \mathrm{OD}\right) \delta \mathrm{ppm}:$

138.6 (x2), 128.0 (x2), 86.7 (x2), 78.4 (x2), 77.2 (x2), 74.5 (x2), $51.3(\mathrm{x} 2), 50.6$ (x2), $36.1(\mathrm{x} 2)$.

HRMS (FAB) $\mathrm{m} / \mathrm{e}$ calcd for $\mathrm{C}_{20} \mathrm{H}_{34} \mathrm{~N}_{4} \mathrm{O}_{6}\left(\mathrm{M}+\mathrm{H}^{+}\right)$427.2556, found 427.2556.

IR (net): 3400 (br), $1099 \mathrm{~cm}^{-1}$.

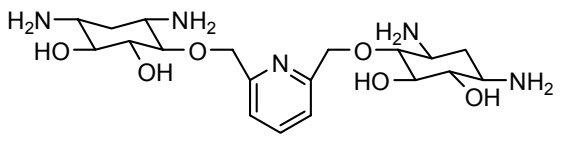

Yield $80 \%$, colorless foam.

10b

${ }^{1} \mathbf{H}$ NMR $\left(500 \mathrm{MHz}, \mathrm{CD}_{3}\right.$ OD) $\delta \mathrm{ppm}$ :

$7.82(\mathrm{t}, \mathrm{J}=10.0,1 \mathrm{H}), 7.41(\mathrm{~d}, \mathrm{~J}=10.5,2 \mathrm{H}), 5.02(\mathrm{~d}, \mathrm{~J}=10.5,2 \mathrm{H}), 4.85(\mathrm{~d}, \mathrm{~J}=$ $10.5,2 \mathrm{H}), 3.41(\mathrm{t}, \mathrm{J}=9.8,2 \mathrm{H}), 3.07-3.12(\mathrm{~m}, 4 \mathrm{H}), 2.78-2.80(\mathrm{~m}, 2 \mathrm{H}), 2.60-2.64$ $(\mathrm{m}, 2 \mathrm{H}), 2.00$ (ddd, $\mathrm{J}=4.4,4.4,12.8,2 \mathrm{H}), 1.21(\mathrm{q}, \mathrm{J}=12.4,2 \mathrm{H})$.

${ }^{13}$ C NMR $\left(125 \mathrm{MHz}, \mathrm{CD}_{3} \mathrm{OD}\right) \delta \mathrm{ppm}$ :

158.1, 138.2 (x2), $121.3(\mathrm{x} 2), 88.3(\mathrm{x} 2), 78.3$ (x2), 76.7 (x2), 74.5 (x2), $51.3(\mathrm{x} 2)$, $50.7(\mathrm{x} 2), 36.4(\mathrm{x} 2)$.

HRMS (ESI): $\mathrm{m} / \mathrm{e}$ calcd for $\mathrm{C}_{19} \mathrm{H}_{33} \mathrm{~N}_{5} \mathrm{O}_{6}\left(\mathrm{M}+\mathrm{H}^{+}\right)$428.2509, found 428.2528 . 
IR (net): 3380 (br), $1110 \mathrm{~cm}^{-1}$.

Yield $83 \%$, colorless foam.

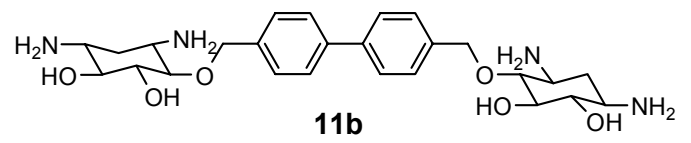

${ }^{1} \mathbf{H}$ NMR $\left(400 \mathrm{MHz}, \mathrm{CD}_{3} \mathrm{OD}\right) \delta \mathrm{ppm}:$

7.60-7.65 (m, 2H), 7.31-7.41 (m, 4H), 7.18-7.20 (m, 2H), 4.77-4.80 (m, 2H),

4.38-4.58 (m, 2H), 3.18-3.22 (m, 2H), 2.98-3.00 (m, 2H), 2.75-2.82 (m, $2 \mathrm{H})$,

$2.45-2.60(\mathrm{~m}, 4 \mathrm{H}), 1.80-1.90(\mathrm{~m}, 2 \mathrm{H}), 1.03-1.10(\mathrm{~m}, 2 \mathrm{H})$.

${ }^{13} \mathrm{C}$ NMR $\left(100 \mathrm{MHz}, \mathrm{CD}_{3} \mathrm{OD}\right) \delta \mathrm{ppm}:$

$140.4,140.2,136.9,136.5,130.1,129.8,129.6,129.4,129.2,127.7,127.4,127.3$, 86.7, 86.6, 78.4, 78.3, 76.8, 76.7, 76.6, 72.7, 72.6, 72.4, 51.3, 51.2, 36.1, 36.0.

HRMS (FAB): $\mathrm{m} / \mathrm{e}$ calcd for $\mathrm{C}_{26} \mathrm{H}_{38} \mathrm{~N}_{4} \mathrm{O}_{6}\left(\mathrm{M}+\mathrm{H}^{+}\right)$503.2870, found 503.2870.

IR (net): 3400 (br), $1088 \mathrm{~cm}^{-1}$.

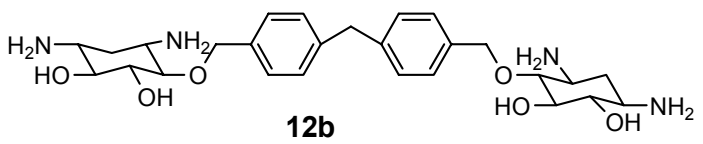

Yield $86 \%$, colorless foam.

${ }^{1} \mathbf{H}$ NMR $\left(400 \mathrm{MHz}, \mathrm{CD}_{3} \mathrm{OD}\right) \delta \mathrm{ppm}$ :

$7.35(\mathrm{~d}, \mathrm{~J}=10.5,4 \mathrm{H}), 7.20(\mathrm{~d}, \mathrm{~J}=10.5,4 \mathrm{H}), 5.02(\mathrm{~d}, \mathrm{~J}=12.0,2 \mathrm{H}), 4.65(\mathrm{~d}, \mathrm{~J}=$ 12.0, 2H), 3.98 (s, 2H), 3.35 (m, 2H), $3.06(\mathrm{t}, 4 \mathrm{H}), 2.59-2.72(\mathrm{~m}, 4 \mathrm{H}), 1.98$ (ddd, J $=4.4,4.4,13.0,2 \mathrm{H}), 1.20(\mathrm{q}, \mathrm{J}=12.4,2 \mathrm{H})$.

${ }^{13} \mathrm{C}$ NMR $\left(100 \mathrm{MHz}, \mathrm{CD}_{3} \mathrm{OD}\right) \delta \mathrm{ppm}$ :

$141.1(\mathrm{x} 2), 137.2$ (x2), 128.7 (x2), 128.3 (x2), 86.7 (x2), 78.4 (x2), 77.2 (x2), 74.6 (x2), $51.3(\mathrm{x} 2), 50.6(\mathrm{x} 2), 41.0,36.1(\mathrm{x} 2)$.

HRMS (FAB): $\mathrm{m} / \mathrm{e}$ calcd for $\mathrm{C}_{27} \mathrm{H}_{40} \mathrm{~N}_{4} \mathrm{O}_{6}\left(\mathrm{M}+\mathrm{H}^{+}\right)$517.3026, found 517.3012.

IR (net): 3380 (br), $1090 \mathrm{~cm}^{-1}$.

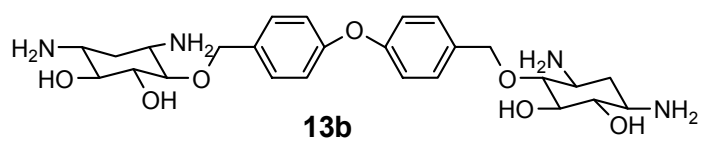

Yield $80 \%$, colorless foam.

${ }^{1} \mathbf{H}$ NMR $\left(500 \mathrm{MHz}, \mathrm{CD}_{3}\right.$ OD) $\delta \mathrm{ppm}$ :

$7.40(\mathrm{~d}, \mathrm{~J}=10.5,4 \mathrm{H}), 6.98(\mathrm{~d}, \mathrm{~J}=10.5,4 \mathrm{H}), 5.01(\mathrm{~d}, \mathrm{~J}=12.0,2 \mathrm{H}), 4.68(\mathrm{~d}, \mathrm{~J}=$ 12.0, $2 \mathrm{H}), 3.35(\mathrm{~m}, 2 \mathrm{H}), 3.08(\mathrm{t}, 4 \mathrm{H}), 2.59-2.72(\mathrm{~m}, 4 \mathrm{H}), 1.98(\mathrm{ddd}, \mathrm{J}=4.4,4.4$, $13.0,2 \mathrm{H}), 1.20(\mathrm{q}, \mathrm{J}=12.4,2 \mathrm{H})$.

${ }^{13} \mathbf{C}$ NMR (125 MHz, CD 3 OD) $\delta \mathrm{ppm:}$

157.1 (x2), 134.2 (x2), 129.8 (x2), 118.5 (x2), 86.6 (x2), 78.4 (x2), 77.2 (x2), 74.2 (x2), $51.3(\mathrm{x} 2), 50.6(\mathrm{x} 2), 36.1(\mathrm{x} 2)$.

HRMS (ESI) $\mathrm{m} / \mathrm{e}$ calcd for $\mathrm{C}_{26} \mathrm{H}_{38} \mathrm{~N}_{4} \mathrm{O}_{6}\left(\mathrm{M}+\mathrm{H}^{+}\right)$519.2819, found 519.2806. 
IR (net): 3390 (br), $1089 \mathrm{~cm}^{-1}$.

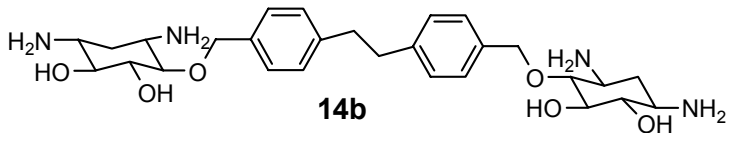

Yield $85 \%$, colorless foam.

${ }^{1} \mathbf{H}$ NMR $\left(500 \mathrm{MHz}, \mathrm{CD}_{3}\right.$ OD) $\delta \mathrm{ppm}$ :

$7.30(\mathrm{~d}, \mathrm{~J}=10.5,4 \mathrm{H}), 7.18(\mathrm{~d}, \mathrm{~J}=10.5,4 \mathrm{H}), 5.00(\mathrm{~d}, \mathrm{~J}=12.0,2 \mathrm{H}), 4.61(\mathrm{~d}, \mathrm{~J}=$ $12.0,2 \mathrm{H}), 3.35(\mathrm{~m}, 2 \mathrm{H}), 3.06(\mathrm{t}, 4 \mathrm{H}), 2.90(\mathrm{~s}, 4 \mathrm{H}), 2.59-2.71(\mathrm{~m}, 4 \mathrm{H}), 1.98$ (ddd, J

$=4.4,4.4,13.0,2 \mathrm{H}), 1.19(\mathrm{q}, \mathrm{J}=12.4,2 \mathrm{H})$.

${ }^{13} \mathrm{C}$ NMR (125 MHz, $\left.\mathrm{CD}_{3} \mathrm{OD}\right) \delta \mathrm{ppm}$ :

141.3 (x2), 136.6 (x2), 128.4 (x2), 128.1 (x2), 86.7 (x2), 78.5 (x2), 77.2 (x2), 74.7 (x2), $51.3(\mathrm{x} 2), 50.6(\mathrm{x} 2), 37.5(\mathrm{x} 2), 36.2(\mathrm{x} 2)$.

HRMS (ESI): $\mathrm{m} / \mathrm{e}$ calcd for $\mathrm{C}_{28} \mathrm{H}_{42} \mathrm{~N}_{4} \mathrm{O}_{6}\left(\mathrm{M}+\mathrm{H}^{+}\right)$531.3183, found 531.3163.

IR (net): 3400 (br), $1110 \mathrm{~cm}^{-1}$.

Synthesis of monomeric deoxystreptamine derivative:
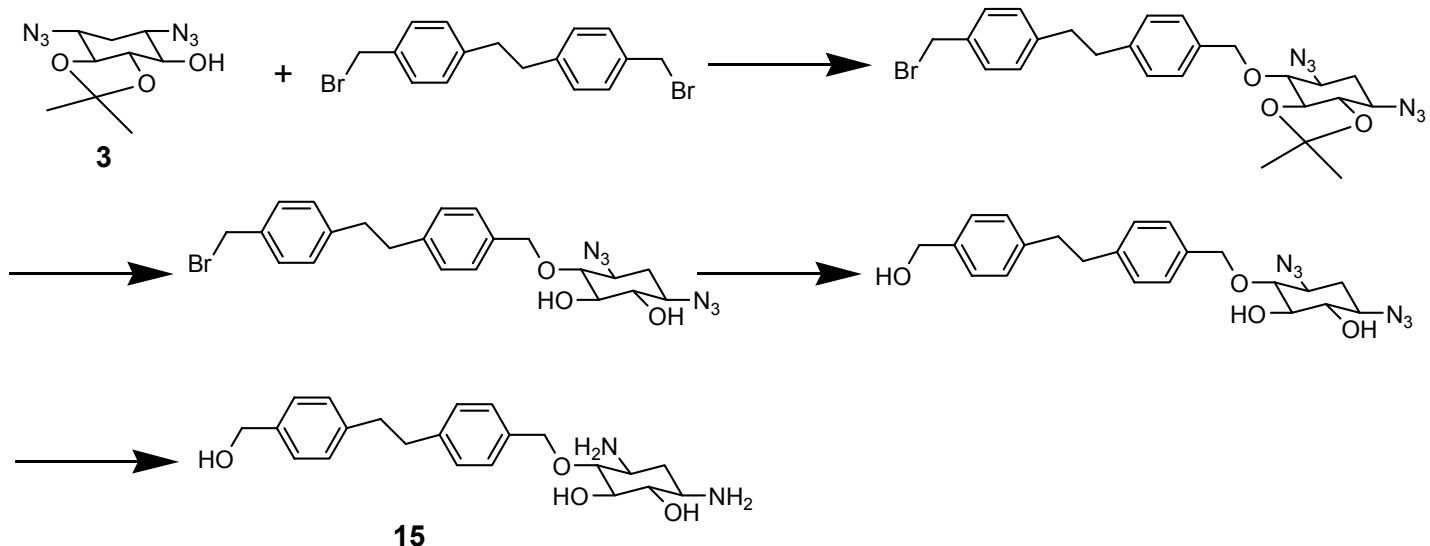

To a solution of starting material $3(0.25 \mathrm{~g}, 0.98 \mathrm{mmol}), \mathrm{NaH}(0.20 \mathrm{~g}, 4.92 \mathrm{mmol}$, $60 \%$ dispersion in mineral oil), catalytic amount of TBAI in anhydrous DMF, was added 4,4'-bis(bromomethyl)dibenzyl $(0.47 \mathrm{~g}, 1.28 \mathrm{mmol})$. The mixture was stirred at $\mathrm{rt}$ for 2 $\mathrm{h}$. The reaction mixture was poured into a solution of ice water and ether. The organic layer was washed with brine, and dried over $\mathrm{Na}_{2} \mathrm{SO}_{4}$. Removal of the solvent followed purification with gradient column chromatography (5-10\% ethyl acetate in hexanes) provided the pure product $0.21 \mathrm{~g}(40 \%) . \mathrm{R}_{\mathrm{f}} 0.25$ ( $25 \%$ ethyl acetate in hexanes).

To a solution of this product $(0.21 \mathrm{~g}, 0.5 \mathrm{mmol})$ in $2: 1$ dioxane-water $(10 \mathrm{~mL})$ was added glacial acetic acid $(8 \mathrm{~mL})$ and the mixture was stirred at $75-80{ }^{\circ} \mathrm{C}$ for $10 \mathrm{~h}$. The reaction mixture was concentrated to dryness gave a residue $0.19 \mathrm{~g}(100 \%)$, which was pure enough and used directly to next step. $\mathrm{R}_{\mathrm{f}} 0.25\left(10 \% \mathrm{MeOH}\right.$ in $\left.\mathrm{CH}_{2} \mathrm{Cl}_{2}\right)$. 
White foam.

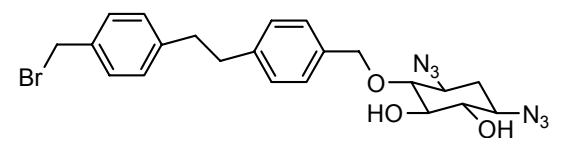

${ }^{1}$ H NMR (500 MHz, CD 3 OD) $\delta$ ppm:

$7.30(\mathrm{~d}, \mathrm{~J}=10.0,2 \mathrm{H}), 7.21(\mathrm{~d}, \mathrm{~J}=10,2 \mathrm{H}), 7.10-7.15(\mathrm{~m}, 4 \mathrm{H}), 4.90(\mathrm{~d}, \mathrm{~J}=12.0$, $1 \mathrm{H}), 4.75(\mathrm{~d}, \mathrm{~J}=12.0,1 \mathrm{H}), 4.58(\mathrm{~s}, 2 \mathrm{H}), 3.43-3.50(\mathrm{~m}, 1 \mathrm{H}), 3.38(\mathrm{t}, 2 \mathrm{H}), 3.20-$ $3.30(\mathrm{~m}, 2 \mathrm{H}), 2.90(\mathrm{~s}, 4 \mathrm{H}), 2.10(\mathrm{ddd}, \mathrm{J}=4.4,4.4,13.0,1 \mathrm{H}), 1.12$ (q, $\mathrm{J}=12.4$, $1 \mathrm{H})$.

${ }^{13}$ C NMR (125 MHz, CD 3 OD) $\delta$ ppm:

$141.3,140.9,138.9,136.1,128.4,128.3,126.9,84.1,76.7,76.2,74.8,63.9,60.8$, $60.4,37.6,37.5,32.3$.

HRMS (ESI): $\mathrm{m} / \mathrm{e}$ calcd for $\mathrm{C}_{22} \mathrm{H}_{25} \mathrm{BrN}_{6} \mathrm{O}_{3}(\mathrm{M}+\mathrm{Na}) 524.1620$, found 524.1626.

IR $\left(\mathrm{CH}_{2} \mathrm{Cl}_{2}\right): 3400$ (br), 2102, $1099 \mathrm{~cm}^{-1}$.

In $20 \mathrm{~mL}$ of 1:1 dioxane/water were refluxed the above monomer compound $(0.19 \mathrm{~g}, 0.38 \mathrm{mmol})$ and $\mathrm{CaCO}_{3}(5.0 \mathrm{~g}, 50 \mathrm{mmol})$ for $10 \mathrm{~h}$, filtered, the solvent was removed under reduced pressure, and the residue was extracted with ether $(3 \times 20 \mathrm{~mL})$ and dried over $\mathrm{Na}_{2} \mathrm{SO}_{4}$. The solvent was removed and purified by silica gel to give colorless foam $0.14 \mathrm{~g}(85 \%)$.

The above compound $(0.14 \mathrm{~g}, 0.32 \mathrm{mmol})$ was dissolved in 4:1 THF-water (5 $\mathrm{mL})$ and $0.1 \mathrm{M}$ aqueous $\mathrm{NaOH}(0.5 \mathrm{~mL})$. $\mathrm{PMe}_{3}(1 \mathrm{M}$ in THF, 5 equivalences $)$ was then added. The reaction mixture was stirred at $45-50{ }^{\circ} \mathrm{C}$ for $5 \mathrm{~h}$, and when complete the reaction mixture was cooled to $\mathrm{rt}$ and loaded on a short column $(5 \mathrm{~cm}$ in height) packed silica gel and Celite. The column was eluted with a series of solutions as the follows: THF, THF/MeOH, MeOH, and $\mathrm{MeOH} /$ conc. $\mathrm{NH}_{4} \mathrm{OH}$ (from $0-10 \%$ of conc. $\mathrm{NH}_{4} \mathrm{OH}$ ). The fractions containing desired product were analyzed by TLC and collected. Removal of solvents gave the final product $0.10 \mathrm{~g}(82 \%)$. $\mathrm{R}_{\mathrm{f}} 0.30\left(25 \% \mathrm{NH}_{4} \mathrm{OH}\right.$ in $\left.\mathrm{MeOH}\right)$.

White foam.

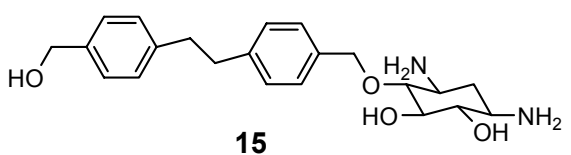

${ }^{1}$ H NMR $\left(500 \mathrm{MHz}, \mathrm{CD}_{3}\right.$ OD) $\delta$ ppm:

$7.30(\mathrm{~d}, \mathrm{~J}=10.0,2 \mathrm{H}), 7.20(\mathrm{~d}, \mathrm{~J}=10,2 \mathrm{H}), 7.12-7.18(\mathrm{~m}, 4 \mathrm{H}), 4.90(\mathrm{~d}, \mathrm{~J}=12.0$, $1 \mathrm{H}), 4.78(\mathrm{~d}, \mathrm{~J}=12.0,1 \mathrm{H}), 4.58(\mathrm{~s}, 2 \mathrm{H}), 3.47-3.52(\mathrm{~m}, 1 \mathrm{H}), 3.40(\mathrm{t}, 2 \mathrm{H}), 3.20-$ $3.31(\mathrm{~m}, 2 \mathrm{H}), 2.90(\mathrm{~s}, 4 \mathrm{H}), 2.12(\mathrm{ddd}, \mathrm{J}=4.4,4.4,13.0,1 \mathrm{H}), 1.25(\mathrm{q}, \mathrm{J}=12.4$, $1 \mathrm{H})$.

${ }^{13}$ C NMR (125 MHz, $\left.\mathrm{CD}_{3} \mathrm{OD}\right) \delta \mathrm{ppm}$ :

$141.3,140.9,138.9,136.1,128.4,128.3,126.9,84.0,76.7,76.2,74.8,63.9,61.7$, $60.8,60.4,37.5,37.4,32.4$.

HRMS (ESI): $\mathrm{m} / \mathrm{e}$ calcd for $\mathrm{C}_{22} \mathrm{H}_{30} \mathrm{~N}_{2} \mathrm{O}_{4}\left(\mathrm{M}+\mathrm{H}^{+}\right)$387.2284, found 387.2278 .

IR (net): 3410 (br), $1100 \mathrm{~cm}^{-1}$.

\section{Reference:}

(1) Peng, K.; Chen, S.; Fann, W. J Am. Chem. Soc. 2001, 123(46), 11388-11397. 
(2) Beever, W. H.; Stille, J. K. Macromolecules, 1979, 12(6), 1033-1038.

(3) Greenberg, W. A.; Priestley, E. S.; Sears, P. S.; Alper, P. B.; Rosenbohm, C.; Hendrix, M.; Hung, S. C.; Wong, C. H. J. Am. Chem. Soc. 1999, 121(28), 65276541. 


\section{Protocols for RNA binding and footprinting experiments}

\section{Materials}

All reagents were obtained from Fisher unless otherwise stated. All solutions were made with Milli-Q purified water. Aminoglycosides were purchase from Sigma, and all RNA was purchased from Dharmacon Research.

\section{Fluorescence Binding Assay}

The ligand solutions were prepared as serial dilutions in $\mathrm{TM}_{1}$ buffer $(10 \mathrm{mM}$ Tris, $1 \mathrm{mM} \mathrm{MgCl} 2, \mathrm{pH} \mathrm{7.5)}$ at a concentration four times greater than the desired final concentration, to allow for the subsequent dilution during the addition of the RNA solution. $50 \mu \mathrm{L}$ of the appropriate ligand solution was then added to a well of a black 96 well plate (Nunc 237105). Refolding of the RNA was preformed using a thermocycler as follows. The RNA, stored in $10 \mathrm{mM}$ Tris, $0.5 \mathrm{mM}$ EDTA, $\mathrm{pH} 7.5$, was first denatured by heating to $95^{\circ} \mathrm{C}$ for $2 \mathrm{~min}$; the temperature was then dropped $0.1^{\circ} \mathrm{C} / \mathrm{sec}$ until the temperature reached $25^{\circ} \mathrm{C}$. After refolding, the RNA was diluted to working concentration of $37.5 \mathrm{nM}$ through addition of the appropriate amount of $\mathrm{TM}_{1}$ buffer $(<4$ $\mu \mathrm{L}$ added into $1900 \mu \mathrm{L}$ of buffer). The tube was mixed by inversion, and then $150 \mu \mathrm{L}$ of the RNA solution was added to each well containing ligand. This subsequent dilution brought the final RNA concentration to $28 \mathrm{nM}$. The fluorescence was measured on a Criterion Analyst AD (Molecular Devices) with an excitation filter of $485 \pm 15 \mathrm{~nm}$, an emission filter of $530 \pm 15 \mathrm{~nm}$, and a $505 \mathrm{~nm}$ dichroic cutoff mirror. The binding was allowed to proceed to equilibrium, which was monitored in $15 \mathrm{~min}$ intervals. Equilibrium was determined when three identical curve were obtained. All curves were fit to a single site model using TableCurve 2D v5.01 (equation 8108):

$$
\mathrm{y}=\mathrm{a}^{*} \mathrm{x} / \mathrm{K}_{\mathrm{d}}+\mathrm{x}
$$

where a is the asymptotic limit. All binding assay were performed in quadruplicate.

Competition binding assay were performed as described above with minor changes. Two RNA oligonucleotides (5'CGCGC3' and 5'GCGCG3') were annealed together using the thermocycler conditions described above. The annealed stem and RNA hairpin loop where then added to $1900 \mu \mathrm{L}$ of $\mathrm{TM}_{1}$ buffer. The tube was mixed by inversion, and then $150 \mu \mathrm{L}$ of the RNA solution was added to each well containing ligand. This subsequent dilution brought the final RNA hairpin concentration to $28 \mathrm{nM}$ and the competing stem concentration to $1 \mu \mathrm{M}$.

\section{Footprint Assay}

The RNA was 5' radiolabeled with $\gamma$-ATP (Amersham Biosciences) using T4 polynucleotide kinase (Invitrogen) according to manufacturer protocols. The protocol for footprinting is largely derived from McPike M. P. et al, Methods in Enzymology 2001, 340, 431-449. The proper RNase concentration and reaction time to yield 'single-hit' 
kinetics $(<20 \%$ enzymatic digestion) were determined first by varying RNase concentration in a series of 1:10 dilution in $\mathrm{TM}_{1}$ with a constant digestion time of $1 \mathrm{~min}$. When necessary the most optimal RNase concentration was held constant and time was varied until 'single-hit' kinetics were obtained.

The ligand solutions were prepared as serial dilutions in $\mathrm{TM}_{5}(10 \mathrm{mM}$ Tris, $5 \mathrm{mM}$ $\mathrm{MgCl}_{2}, \mathrm{pH}$ 7.5) at a concentration 2.5 times greater than the desired final concentration, to allow for the subsequent dilution during the addition of the RNA solution. $4 \mu \mathrm{L}$ of the appropriate ligand solution were added a well of a 96 well V-bottom plate (Nunc 249662). Refolding of the RNA was preformed using a thermocycler. The RNA, stored in $10 \mathrm{mM}$ Tris, $0.5 \mathrm{mM}$ EDTA, pH 7.5 was first denatured by heating to $95^{\circ} \mathrm{C}$ for $2 \mathrm{~min}$ after which the temperature was dropped $0.1^{\circ} \mathrm{C} / \mathrm{sec}$ until the temperature reached $25^{\circ} \mathrm{C} .5$ $\mu \mathrm{L}$ of the refolded RNA was added to each well containing ligand. Binding was allowed to proceed for $30 \mathrm{~min}$. After incubation, $1 \mu \mathrm{L}$ of RNase is added to each well and the digestion is stopped by the addition of Stop Buffer ( 8 M Urea, $50 \mathrm{mM}$ EDTA, 2X TBE, bromphenol blue $0.05 \%(\mathrm{w} / \mathrm{v})$, and xylene cyanol $0.05 \%(\mathrm{w} / \mathrm{v}))$. The concentration of RNase and digestion time are those that yield 'single-hit' kinetics. $18 \mu \mathrm{L}$ of each sample were then run on a $20 \%$ Acrylamide (29:1), $8 \mathrm{M}$ Urea gel at $45 \mathrm{~V}$ for 5.25 hours. Gels were analyzed by Molecular Dynamics Storm 430 phosphoimager (Amersham Biosciences).

Densitometeric analysis of G10 was performed using ImageQuant 5.2 (Molecular Dynamics). The resulting intensity profile was then fit a single-site model (see above), however due to the relatively poor fit $\left(\mathrm{R}^{2}=.869\right)$ an approximate $\mathrm{K}_{\mathrm{d}}$ is given. 